\title{
Acta
Biochimica
Polonica
}

Vol. 50 No. 1/2003

$239-247$

www.actabp.pl

\section{Expression in Escherichia coli of human ARHGAP6 gene and purification of His-tagged recombinant protein ${ }^{*}$}

\author{
Anna-Maria Ochocka, Marzena Czyżewska and Tadeusz Pawełczyk ${ }^{\bowtie}$ \\ Department of Molecular Medicine, Medical University of Gdańsk, Gdańsk, Poland
}

Received: 15 November, 2002; accepted: 12 February, 2003

Key words: ARHGAP6, His-tag, IbpA, IbpB

\begin{abstract}
In this report we describe cloning and expression of human Rho GTPase activating protein (ARHGAP6) isoform 4 in Escherichia coli cells as a fusion protein with 6xHis. We cloned the ARHGAP6 cDNA into the bacterial expression vector pPROEX-1. Induction of the 6xHis-ARHGAP6 protein in BL21(DE3) and DH5 $\alpha$ cells caused lysis of the cells irrespective of the kind of culture medium used. Successful expression of the fusion protein was obtained in the MC4100 $\triangle$ ibp mutant strain lacking the small heat-shock proteins IbpA and IbpB. Reasonable yield was obtained when the cells were cultured in Terrific Broth $+1 \%$ glucose medium at $22^{\circ} \mathrm{C}$ for $16 \mathrm{~h}$. The optimal cell density for expression of soluble 6xHis-ARHGAP6 protein was at $A_{600}$ about 0.5 . Under these conditions over $90 \%$ of the fusion protein was present in a soluble form. The 6xHis-ARHGAP6 protein was purified to near homogeneity by a two step procedure comprising chromatography on Ni-nitrilotriacetate and cation exchange columns. The expression system and purification procedure employed made it possible to obtain 1-2 $\mathrm{mg}$ of pure 6xHis-ARHGAP6 protein from $300 \mathrm{ml}$ (1.5 $\mathrm{g}$ of cells) of $E$. coli culture.
\end{abstract}

Small monomeric G-proteins cycle between the GDP-bound inactive form and the GTP-bound active one. The activation signal causes GDP to be exchanged for GTP. Hydrolysis of GTP by an intrinsic GTPase activity returns the G-protein to the inactive state, but for typical small G-proteins the rate of GTP hydrolysis is extremely low (Sweet et al., 1984). GTPase-activating proteins (GAPs) are accessory proteins catalyzing the formation of inactive G-protein by stimulating its GTPase activity (Trahey \& McCormick, 1987).

Rho proteins are members of the superfamily of small G-proteins. At least three types

\footnotetext{
This work was supported by the State Committee for Scientific Research (KBN, Poland) grant No. 6P04B02620 to M.C.

${ }^{\star}$ To whom correspondence should be addressed: Department of Molecular Medicine, Medical University of Gdańsk, ul. Dębinki 7 paw. 29, 80-211 Gdańsk, Poland; tel.: (48 58) 349 2750, fax: (48 58) 349 2759, e-mail: tkpaw@amg.gda.pl
}

Abbreviations: GAPs, GTPase-activating proteins; PI, phosphatidylinositol. 
of Rho protein are known, A, B, and C. Rho is involved in controlling of cytoskeletal organization. Microinjection of Rho into mammalian cells causes rapid and dramatic changes in cell shape, forming finger-like polarized cytoplasmic extensions (Paterson et al., 1990; Miura et al., 1993). Inactivation of endogenous Rho (by ADP-ribosylation via microinjection of botulin ADP-ribosyltransferase C3) causes dissolution of actin filaments, and cells to round up (Rubin et al., 1988; Paterson et al., 1990). In addition, Rho has been demonstrated to influence phosphatidylinositol (PI) metabolism by enhancing the activity of PI 4-phosphate 5-kinase (Chong et al., 1994). On the other hand, the p122 GAP specific for Rho possesses the ability to interact with $\delta$-1 isoform of phospholipase C (PLC $\delta 1$ ) and enhance its activity (Homma \& Emori, 1995). Recently, a novel GTPase-activating protein gene named ARHGAP6 specific for RhoA has been identified (Schaefer et al., 1997; Prakash et al., 2000).

In order to obtain reasonable quantities of pure ARHGAP6 protein needed to study its interaction with PLC $\delta 1$ we developed a bacterial expression system. Isoform 4 of human ARHGAP6 protein was expressed in Escherichia coli cells and purified to homogeneity.

\section{MATERIALS AND METHODS}

Leupeptin, isopropyl $\beta$-D-thiogalactopyranoside, ampicillin, alkaline phosphatase-conjugated goat anti-rabbit IgG, 5-bromo-4-chloro3-indolyl phosphate, and Nitro Blue Tetrazolium were from Sigma-Aldrich Sp. z o.o. (Poznań, Poland). Pefabloc SC was from Roche Applied Science (Mannhein, Germany). E. coli QC771 $\Delta i b p A / B$ and MC4$100 \Delta i b p A / B$ were kindly provided by Dr. Ewa Laskowska (Biochemistry Department, University of Gdansk). E. coli strains BL21(DE3), DH5 $\alpha$, pPROEX-1 vector, $\mathrm{Ni}^{2+}$-NTA resin, rTEV protease, oligo(dT), and dNTPs were from Invitrogen (Carlsbad, CA, U.S.A.).
Immobilon-P Transfer Membrane was from Millipore Corp. (Bedford, MA, U.S.A.). E. coli Qiagen EZ cells and PCR Cloning Kit were from Qiagen GmbH (Hilden, Germany). All primers were from Integrated DNA Technologies, Inc. (Coralville, IA, U.S.A.). Total RNA Prep Plus Kit, Plasmid Miniprep Plus and DNA Clean-Up Kit were from A\&A Biotechnology (Gdansk, Poland). Moloney murine leukemia virus reverse transcriptase (MMLV-RT), and Tth DNA polymerase were from Epicentre Technologies (Madison, WI, U.S.A.). RNasin was from Promega (Madison, WI, U.S.A.). NdeI and XhoI were from Fermentas AB (Vilnius, Lithuania). All other reagents were of analytical grade.

$R N A$ extraction and reverse transcription. Total RNA was extracted from human blood cells with the use of Total RNA Prep Plus Kit and stored at $-40^{\circ} \mathrm{C}$. Reverse transcription was performed in $20 \mu \mathrm{l}$ final volume of $50 \mathrm{mM}$ Tris/ $\mathrm{HCl}, \mathrm{pH} 8.3,75 \mathrm{mM} \mathrm{KCl}, 3 \mathrm{mM}$ $\mathrm{MgCl}_{2}, 10 \mathrm{mM}$ dithiothreitol (DTT), $1 \mathrm{mM}$ dNTPs, $250 \mathrm{ng}$ oligo(dT), 14 units of reverse transcriptase (MMLV-RT), 10 units of RNasin, and 1-5 $\mu \mathrm{g}$ of RNA. Reactions were incubated for $45 \mathrm{~min}$ at $42^{\circ} \mathrm{C}$ and $5 \mathrm{~min}$ at $95^{\circ} \mathrm{C}$.

Cloning of the ARHGAP6 gene. Unless otherwise indicated, the recombinant DNA methods used were those of Sambrook et al. (1989). In order to obtain cDNA for ARHGAP6 we ran PCR reaction with the primers GAPB3 (GGTGATTTCACCGGATCCAGCATGT, forward) and GAPE2 (GTGCCAGTGGAATTCACCCACGG, reverse). The primers were based on the human cDNA sequence (GeneBank, accession No. AF177663). The PCR reaction was performed in $20 \mu \mathrm{l}$ final volume in $50 \mathrm{mM}$ Tris/ $\mathrm{HCl}, \mathrm{pH} 9.0,20 \mathrm{mM}$ ammonium sulfate, $2.5 \mathrm{mM} \mathrm{MgCl}_{2}, 0.25 \mathrm{mM}$ dNTPs, $1.5 \mathrm{U}$ of Tth DNA polymerase, $0.5 \mu \mathrm{M}$ primers and $1 \mu \mathrm{g}$ of human blood cells cDNA. The PCR consisted of an initial denaturation at $95^{\circ} \mathrm{C}$ for $3 \mathrm{~min}$ and 35 cycles of $45 \mathrm{~s}$ at $95^{\circ} \mathrm{C}$, $60 \mathrm{~s}$ at $63^{\circ} \mathrm{C}, 150 \mathrm{~s}$ at $72^{\circ} \mathrm{C}$, and a final extension of $10 \mathrm{~min}$ at $72^{\circ} \mathrm{C}$. The PCR product 
(2418 bp) was directly cloned into pDrive Cloning Vector using Qiagen PCR Cloning Kit according to the manufacturer's protocol. The pDrive-ARHGAP6 plasmid was produced in Qiagen EZ cells. The cloned cDNA was sequenced and was confirmed to be complete ARHGAP6-encoding cDNA.

In order to clone the ARHGAP6 cDNA into the bacterial expression vector pPROEX-1 (Fig. 1) we generated a restriction enzyme
Cell growth and expression of ARHGAP6. pPROEX-ARHGAP6 was used for the expression of ARHGAP6 as a fusion protein with the $6 x$ His peptide at the amino-terminus. Appropriate E. coli strain was transformed with the above-mentioned plasmid and colonies were grown on agar plates. For BL21(DE3) and DH5 $\alpha$ the agar contained $100 \mu \mathrm{g} / \mathrm{ml}$ ampicillin. For $\mathrm{QC} 771 \Delta i b p A / B$ and $\mathrm{MC} 4100 \Delta i b p A / B$ cells

A

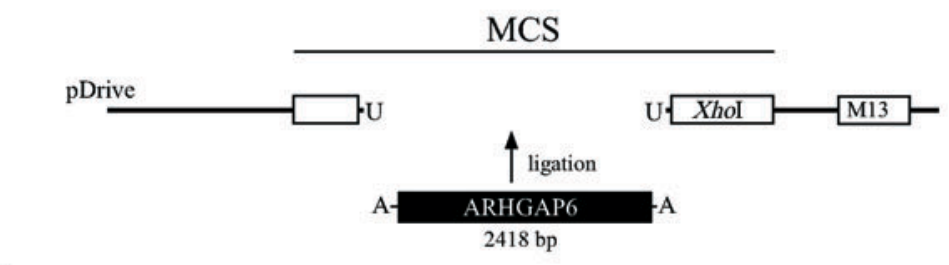

B

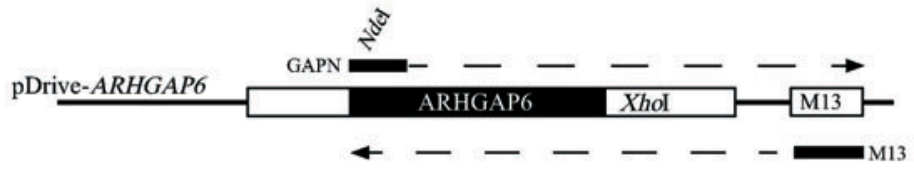

C

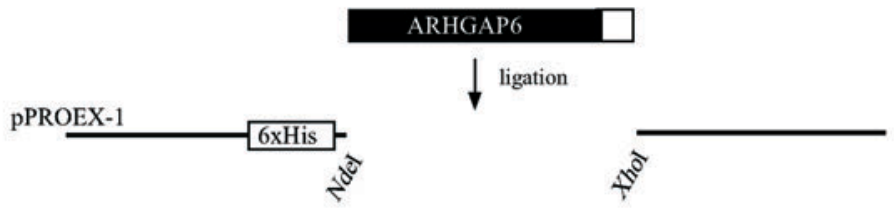

Figure 1. Cloning of ARHGAP6 cDNA into pPROEX-1 vector.

A. Product of PCR (2418 bp) performed on human blood cells cDNA was directly ligated into pDrive cloning vector. MCS, multiple cloning site; M13, M13 primer binding site. The XhoI restriction site in MCS of pDrive is indicated. B. Generation of NdeI restriction site by PCR with GAPN and M13 primers. C. Ligation of ARHGAP6 cDNA into pPROEX-1 vector.

cleavage site for NdeI by running PCR reaction with the primers GAPN (ACCGGATCCCATATGTCAG, forward) and M13F (GTAAAACGACGGCCAGT, reverse). The $\mathrm{PCR}$ reaction was performed as above with 10 ng of pDrive-ARHGAP6. The PCR consisted of an initial denaturation at $95^{\circ} \mathrm{C}$ for $3 \mathrm{~min}$ and 35 cycles of $45 \mathrm{~s}$ at $95^{\circ} \mathrm{C}, 60 \mathrm{~s}$ at $53^{\circ} \mathrm{C}, 180$ $\mathrm{s}$ at $72^{\circ} \mathrm{C}$, and a final extension of $10 \mathrm{~min}$ at $72^{\circ} \mathrm{C}$. The ARHGAP 6 cDNA was then cut with appropriate enzymes and ligated into the unique NdeI and XhoI sites in pPROEX-1 (Fig. 1). the agar contained $100 \mu \mathrm{g} / \mathrm{ml}$ ampicillin, 20 $\mu \mathrm{g} / \mathrm{ml}$ chloramphenicol, and $30 \mu \mathrm{g} / \mathrm{ml}$ streptomycin. Picked colonies were grown overnight at $37^{\circ} \mathrm{C}$ in ampicillin-containing Luria-Bertani (LB) or Terrific Broth supplemented with $1 \%$ glucose (TBG) medium, and 1 $\mathrm{ml}$ of this culture was inoculated into $1 \mathrm{l}$ of fresh medium, and incubated at the desired temperature to an absorbance of 0.5-0.8 (measured at $600 \mathrm{~nm}$ ). Expression of the 6xHis-ARHGAP6 protein was induced by the addition of $1 \mathrm{mM}$ isopropyl- $\beta$-D-thiogalactopyranoside (IPTG). Following induction, the 
cells were grown for an appropriate time and harvested by centrifugation.

Purification of ARHGAP6. All steps were done at $4^{\circ} \mathrm{C}$. Cell pellet from $1 \mathrm{l}$ culture was suspended in $40 \mathrm{ml}$ of buffer A $(50 \mathrm{mM}$ Tris/HCl buffer, $\mathrm{pH} 8.5,0.5 \mu \mathrm{g} / \mathrm{ml}$ leupeptin, $0.2 \mathrm{mM}$ Pefablock SC), placed on powdered dry ice and sonicated. The crude cell extract was clarified by centrifugation at $20000 \times \mathbf{g}$ for $30 \mathrm{~min}$. Clear supernatant was passed through a $5 \mathrm{ml}$ Ni-nitrilotriacetate (Ni-NTA) column preequilibrated with buffer A containing $300 \mathrm{mM} \mathrm{KCl}$ (buffer A1). The column was washed with buffer A1 containing $20 \mathrm{mM}$ imidazole until no more protein was eluted. The 6xHis-ARHGAP6 protein was then eluted with $7 \mathrm{ml}$ of buffer A1 containing $100 \mathrm{mM}$ imidazole. Fractions containing high protein concentration were combined, desalted on Sephadex G-25 M (Pharmacia columns PD-10) previously equilibrated with buffer B (50 mM phosphate buffer, $\mathrm{pH}$ 7.0, $1 \mathrm{mM}$ dithiothreitol, $0.5 \mu \mathrm{g} / \mathrm{ml}$ leupeptin, $0.2 \mathrm{mM}$ Pefablock SC, 20\% glycerol), and applied to a UnoS cation exchange FPLC column equilibrated with buffer B. The column was washed with $10 \mathrm{ml}$ of buffer B and eluted with a linear gradient from 0 to $2 \mathrm{M} \mathrm{KCl}$ over $20 \mathrm{ml}$. The active fractions were pooled and stored at $-20^{\circ} \mathrm{C}$.

Antibodies. Polyclonal antibodies to the 6xHis-ARHGAP6 protein were generated in rabbits. Rabbits were subcutaneously injected in the back of the neck with $400 \mu \mathrm{g}$ of purified recombinant 6xHis-ARHGAP6 protein in Freund's adjuvant followed by three boosts with $200 \mu \mathrm{g}$ of the antigen each every 3 weeks. The antibodies were purified by chromatography on a protein A-agarose column.

SDS/PAGE and immunoblotting. Samples (100 $\mu \mathrm{g}$ of protein) were separated by polyacrylamide gel electrophoresis (8\% acrylamide) in the presence of sodium dodecyl sulfate (SDS/PAGE) (Laemmli, 1970) and then electrophoretically transferred to Immobilon poly(vinylidenedifluoride) (Millipore) transfer membrane. The membrane was blocked with $3 \%$ bovine albumin (fraction V) in phosphate buffered saline (PBS) with $0.02 \%$ $\mathrm{NaN}_{3}$ and then washed with PBS. The blocked membrane strips were incubated with rabbit anti-ARHGAP6 polyclonal antibodies (dilution 1:10000). Immunostaining was done using alkaline phosphatase-conjugated goat anti-rabbit IgG (dilution 1:20000), the chromogenic substrate 5-bromo-4-chloro-3-indolyl phosphate and Nitro Blue Tetrazolium.

E. coli strains. BL21(DE3): $\mathrm{F}^{-}$omp $\mathrm{T}$ $h s d \mathrm{~S}_{\mathrm{B}}\left(\mathrm{r}_{\mathrm{B}}{ }^{-} \mathrm{m}_{\mathrm{B}}{ }^{-}\right.$) gal dcm (DE3); $\mathrm{DH} 5 \alpha: \mathrm{F}^{-}$ Ф80dlacZ $\Delta$ M15 $\Delta$ (lacZYA-argF) U169 deoR recA1 end $\mathrm{A} 1$ hsd $\mathrm{R} 17\left(\mathrm{r}_{\mathrm{k}}{ }^{-}, \mathrm{m}_{\mathrm{k}}{ }^{+}\right)$phoA supE44 $\lambda^{-}$thi-1 gyrA96 relA1; Qiagen EZ: [F'::Tn10( $\left.\mathrm{Tc}^{\mathrm{r}}\right)$ pro $A^{+} B^{+}$lacl $\left.^{\mathrm{q}} \mathrm{Z} \Delta M 15\right]$ recA1 endA1 hsdR 17 ( $\mathrm{r}_{\mathrm{K} 12}{ }^{-} \mathrm{m}_{\mathrm{K} 12}{ }^{+}$) lac glnV44 thi-1 gyrA96 relA1; QC771: $\mathrm{F}^{-} \Delta$ (lac-argF) U169 rpsL179 inversion (rrnD-rrnE)1 sup amb P1 ( $\triangle i b p A / B:: c m) ; M C 4100 A / B:[a r a D 139 \Delta$ (lac POZYA argF) U169 fla relA rpsL] $\triangle i b p:: \mathrm{cmA} / B$.

Analytical. Protein concentration was determined by the method of Bradford (1976) with bovine serum albumin as a standard. DNA and RNA concentrations were determined by measuring the absorbance at $260 \mathrm{~nm}$.

\section{RESULTS}

\section{Expression of 6xHis-ARHGAP6 protein in E. coli cells}

The cDNA of human ARHGAP6 isoform 4 (GeneBank accession No. AF177663) was cloned into pPROEX-1 vector (Fig. 1), which in our laboratory proved to be useful in obtaining several mammalian proteins in $E$. coli cells (Pawelczyk \& Matecki, 1997; Pawelczyk et al., 2000; Sakowicz et al., 2001). Initially, in order to obtain human recombinant ARHGAP6 protein we used the BL21(DE3) cells. However, after transformation with the pPROEX-ARHGAP6 plasmid the cells lysed on LB agar and occasionally single colonies were observed on TB $+1 \%$ glucose (TBG) agar 
plates. Our attempts to culture cells from these colonies in TBG medium at $37^{\circ} \mathrm{C}$ were unsuccessful, because the cells lysed. Similar results were obtained for $\mathrm{DH} 5 \alpha$ cells. These observations indicated that human ARHGAP6 protein is highly toxic to $E$. coli cells. Such a toxicity could be the result of accumulation of native and/or denatured and aggregated ARHGAP6 protein. Recently, it has been demonstrated that small heat-shock proteins (IbpA, IbpB) stabilize denatured and ag-

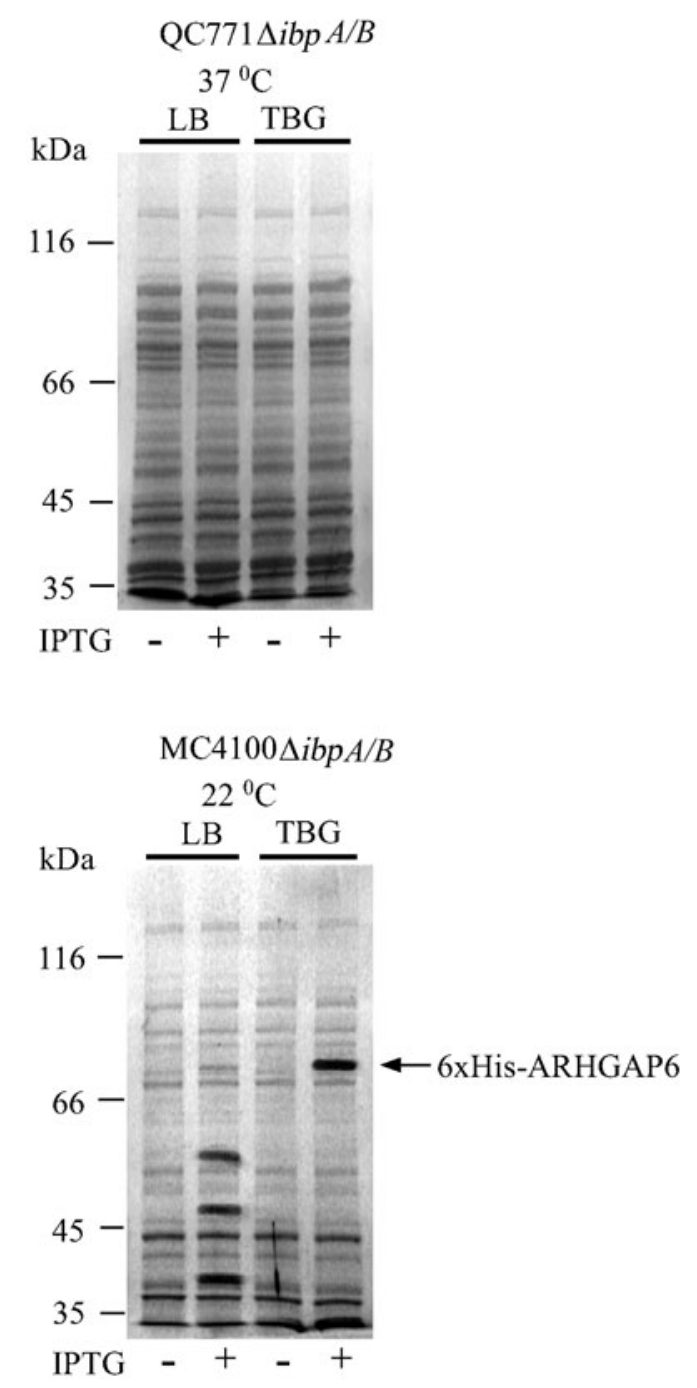

gregated proteins in $E$. coli cells (Kuczynska-Wisnik et al., 2002). Therefore, for the expression of human ARHGAP6 protein we tested the QC771 $\Delta i b p A / B$ and $\mathrm{MC} 4100$ $\triangle i b p A / B$ mutant strains, which do not express both the IbpA and IbpB proteins. After transformation with pPROEX-ARHGAP6 both mutant strains grew as colonies on LB and TBG agar plates (not shown). Induction of the 6xHis-ARHGAP6 protein in MC4100$\triangle i b p A / B$ cells cultured in LB or TBG medium at $37^{\circ} \mathrm{C}$ resulted in obtaining proteins with lower molecular masses than the predicted mass of 6xHis-ARHGAP6 (Fig. 2). Under such conditions no induced proteins were visible in extracts of $\mathrm{QC} 771 \Delta i b p A / B$ cells. A reasonable yield of the 6xHis-ARHGAP6 protein was obtained when MC4100 $\Delta i b p A / B$ cells were cul-

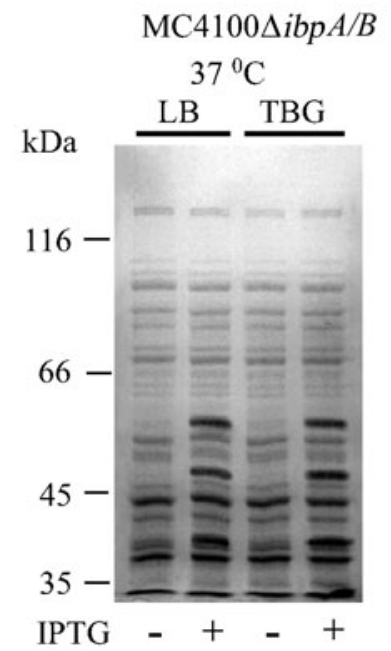

Figure 2. Expression of 6xHis-ARHGAP6 protein in $\mathrm{QC771} \triangle i b p A / B$ and MC4100$\triangle i b p A / B$ cells.

E. coli cells transformed with pPROEX-ARHGAP6 were grown in media and at temperatures indicated until $\mathrm{A}_{600}$ reached 0.5 and the expression of 6xHis-ARHGAP6 protein was induced by adding IPTG. Expression at $37^{\circ} \mathrm{C}$ and at $22^{\circ} \mathrm{C}$ was performed for 3 and $12 \mathrm{~h}$, respectively. Crude cell extracts were prepared and analyzed by $8 \%$ SDS/PAGE. The positions of molecular mass standards are indicated on the left. LB, LuriaBertani medium; TBG, Terrific Broth supplemented with $1 \%$ glucose.

tured in TBG medium at $22^{\circ} \mathrm{C}$ for $16 \mathrm{~h}$ (Fig. 2). The optimal cell density for expression of soluble protein was at a $\mathrm{A}_{600}$ about 0.5; at greater cell densities the amount of the expressed protein decreased sharply. Under these conditions over $90 \%$ of 6 xHis-ARHGAP6 was present as a soluble protein (Fig. 3). There were no 
losses in the yield of 6xHis-ARHGAP6 expression in transformed cells stored on TBG agar plates for up to 6 days at $4^{\circ} \mathrm{C}$. Cells stored on agar plates longer than 6 days produced cultures with a lower yield of the protein.

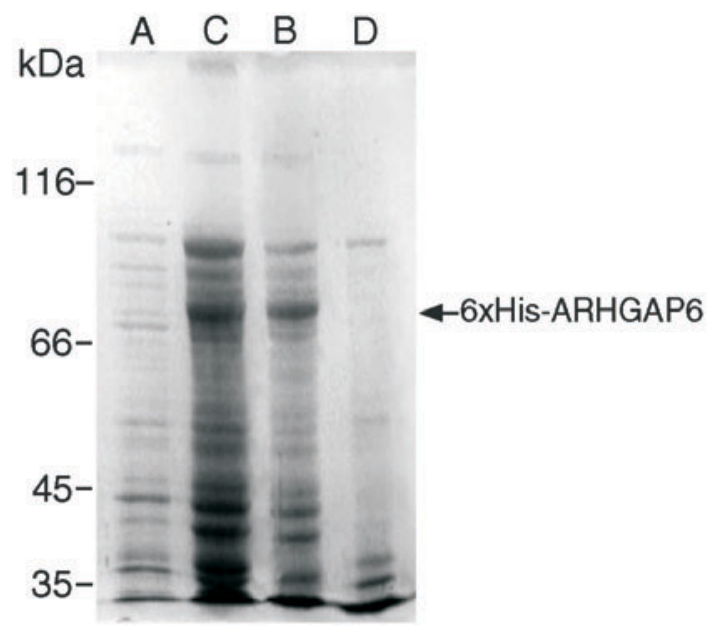

Figure 3. Evaluation of solubility of 6xHisARHGAP6 protein expressed in MC4100 $\triangle i b p A / B$ cells.

MC4100 $\triangle i b p A / B$ cells transformed with pPROEXARHGAP 6 were cultured in TBG medium at $22^{\circ} \mathrm{C}$ until $\mathrm{A}_{600}$ reached 0.5 (lane A). At this point IPTG was added and cells were cultured for $16 \mathrm{~h}$. Crude cell extracts (lane B) and high-speed supernatant (lane C) were prepared and analyzed on $8 \%$ SDS/PAGE. The pellet (lane D) from high-speed centrifugation (30 min, $20000 \times \mathbf{g}$ ) was dissolved in loading buffer (equal volume to initial cell extract volume). On lanes B-D $25 \mu \mathrm{l}$ of sample was loaded. The positions of molecular mass standards are indicated on the left.

\section{Purification of 6xHis-ARHGAP6 protein}

Usually the process of protein purification started with about $1.5 \mathrm{~g}$ of $E$. coli cells obtained from $300 \mathrm{ml}$ culture. Soluble bacterial lysate was first subjected to chromatography on Ni-NTA. The purity and apparent molecular mass of the eluted proteins were checked by SDS/PAGE. The advantage of using His-tagged protein is a relative ease of purification on a metal-affinity column. However, despite extensive washes the fractions eluted by $100 \mathrm{mM}$ imidazole contained also other proteins besides 6xHis-ARHGAP6 (Fig. 4).
Subsequent chromatography on a cation exchange (Uno S) column gave a significant improvement in the purity of the 6xHisARHGAP6 protein. The expression system employed and the described purification pro-

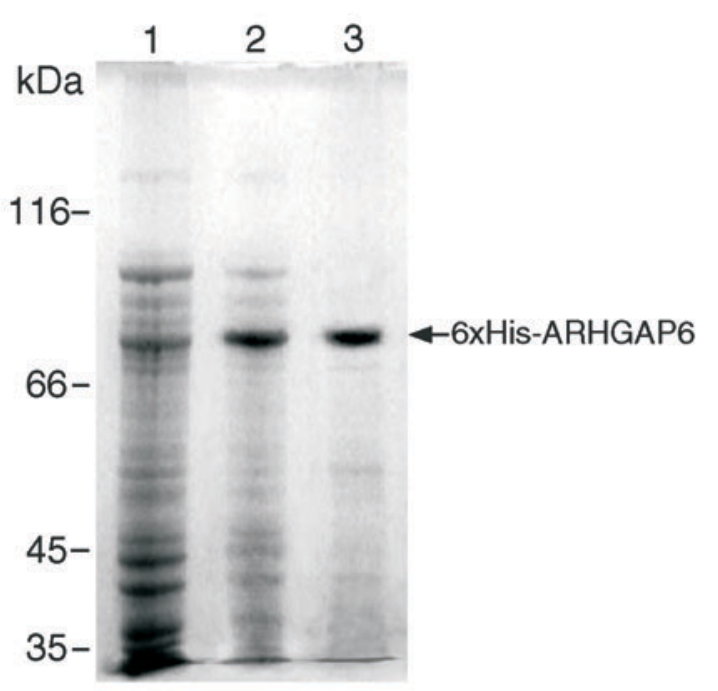

Figure 4. Purification of 6xHis-ARHGAP6 protein expressed in $\boldsymbol{E}$. coli.

Proteins from MC4100 $\triangle i b p A / B$ cells transformed with pPROEX-ARHGAP6 were electrophoresed on $8 \%$ SDS/ PAGE. Expression of 6xHis-ARHGAP6 protein was performed at $22^{\circ} \mathrm{C}$ for $16 \mathrm{~h}$. Individual lanes of the SDS/PAGE contained the following: high-speed supernatant of crude extract of cells expressing 6xHisARHGAP6 protein (lane 1), proteins eluted from the Ni-NTA column by $100 \mathrm{mM}$ imidazole (lane 2), proteins eluted from the cation exchange column (UnoS) by 120 $\mathrm{mM} \mathrm{KCl}$. The positions of molecular mass standards are indicated on the left.

cedure allowed us to obtain 1-2 mg of pure 6xHis-ARHGAP6 protein from $1.5 \mathrm{~g}$ of $E$. coli cells. The purified $6 x$ His-ARHGAP6 protein migrated on $8 \%$ SDS/PAGE as a protein with a molecular mass of $85 \mathrm{kDa}$ (Fig. 4). This is in good agreement with $87.8 \mathrm{kDa}$ calculated from the predicted amino-acid sequence of the recombinant protein.

\section{6xHis-ARHGAP6 antibodies}

The 6xHis-ARHGAP6 protein purified as described above was electrophoresed on $8 \%$ 
PAGE/SDS. The protein bands were visualized with Ponceau S and the 6xHis-ARHGAP6 band was cut out and electroeluted from the gel. The $6 x$ His-ARHGAP6 protein was then used to generate polyclonal antibodies in rabbits. The obtained anti-ARHGAP6 polyclonal antibodies recognized with high specificity the $6 x$ His- ARHGAP6 protein. As can be seen in Fig. 5 the antibodies did not recognize any rat protein. Immunoblot analysis performed on extracts of human blood cells showed the presence of one major (about $85 \mathrm{kDa}$ ) and two minor protein bands (about $100 \mathrm{kDa}$ and about $60 \mathrm{kDa}$ ) reactive with anti-ARHGAP6 (Fig. 5). The protein bands reactive with anti-

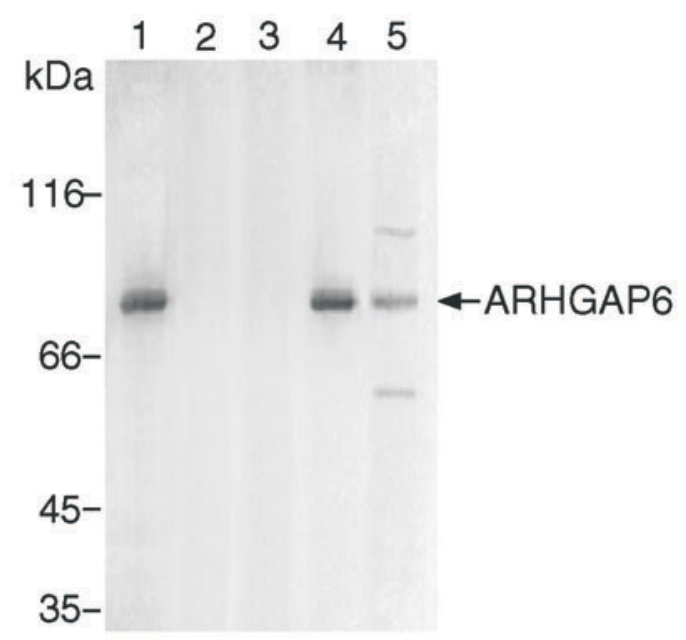

Figure 5. Specificity of anti-ARHGAP6 polyclonal antibodies.

Tissue extracts (50 $\mu \mathrm{g}$ of protein) were subjected to SDS/PAGE (8\%) and transferred to an Immobilon transfer membrane. The membrane was immunoblotted with anti-ARHGAP6 polyclonal antibodies. On lane 1, recombinant ARHGAP6 protein was loaded (30 ng). On lanes 2 and 3, extracts of rat kidney and heart were loaded, respectively. On lane 4, rat kidney extract supplemented with $30 \mathrm{ng}$ of recombinant ARHGAP6 was loaded. On lane 5, extract of human blood cells was loaded. The positions of molecular mass standards are indicated on the left.

ARHGAP6 are likely to be isoforms of ARHGAP6 generated by alternative splicing. Based on cDNA sequences deposited in GeneBank (accession Nos. NM001174, AF022212, $\mathrm{AF} 012272$, AF177663, and AF177665) five isoforms of ARHGAP6 protein with calculated molecular masses of 106, 75.9, 84 (two isoforms) and $62.9 \mathrm{kDa}$ could be predicted to be present in human tissues.

\section{DISCUSSION}

According to our knowledge this is the first report describing expression in $E$. coli cells and purification of human ARHGAP6 protein. The expression and purification system described in this contribution enables obtaining reasonable quantities of soluble $6 x$ HisARHGAP6 protein. The successful expression of this protein was made possible by the use of the MC4100 $\Delta i b p A / B$ mutant strain.

Numerous data indicate that foreign proteins often do not express well in $E$. coli cells. Some proteins when expressed in $E$. coli induce cell lysis. The lysis of non-induced BL21(DE3) cells transformed with pPROEXARHGAP6 observed in our experiments could be due to background expression of the toxic protein (Studier, 1991). Partial improvement of cells stability noted when the transformed cells were cultured in the presence of $1 \%$ glucose supports such an assumption. Decreased background expression of the T7 polymerase gene and improved plasmid stability in BL21(DE3) cells cultured in the presence of $1 \%$ glucose have been reported (Pan \& Malcolm, 2000). The reduction of background expression in BL21 (DE3) cells in the presence of $1 \%$ glucose can be explained by catabolite repression of the lacUV5 promoter, which is a mutated version of the original lac promoter. The mutation ( $\mathrm{G} \rightarrow \mathrm{A}$ at -9 ) reduces lacUV5 dependence on the cAMP/ catabolite gene activator protein (CAP) complex to initiate transcription (Hirschel et al., 1980). Previously it was demonstrated that the affinity of lacUV5 for cAMP/CAP is significantly reduced but not fully abolished (Fried $\&$ Crothers, 1984). Therefore, the cAMP/CAP complexes present in cells growing in media with poor carbon sources (LB, TB) may acti- 
vate to some extent the lacUV5 promoter. Glucose, by decreasing the level of cAMP, suppresses this so-called "promoter leaking".

The lysis of BL21(DE3) cells when expression of the 6xHis-ARHGAP6 protein was induced indicates that this protein is toxic to $E$. coli cells. Such a toxicity could be caused by native 6xHis-ARHGAP6 protein or/and by accumulation of denatured aggregates. The results obtained with the use of MC4100 $\Delta i b A / B$ cells point out rather to the second possibility. The IbpA and IbpB chaperones are small heat-shock proteins (sHSP) whose physiological role in $E$. coli cells is still enigmatic. IbpA and $\mathrm{IbpB}$ are the major components of denatured and aggregated proteins (the $\mathrm{S}$ fraction) accumulating in $E$. coli cells during heat-shock (Kucharczyk et al., 1991; Laskowska et al., 1996) and are found associated with non-native recombinant proteins expressed in bacterial cells (Allen et al., 1992). It was reported that in vitro IbpB oligomers bind and stabilize heat-denatured proteins preventing the irreversible aggregation (Veinger et al., 199ir8). Kitagawa et al. (2002) reported that IbpA and IbpB protected several enzymes against inactivation by heat, oxidants or guanidine hydrochloride. The recently reported data from in vivo experiments on the refolding of heat-denatured fructose-1-6-bisphosphate aldolase indicate that the IbpA/B proteins may inhibit DnaK/DnaJ-dependent refolding of some proteins by blocking DnaK/DnaJ-binding sites in denatured proteins (Kuczynska-Wisnik et al., 2002). These authors also found that mild heat stress produced less aggregated proteins (fraction $\mathrm{S}$ ) in mutant cells not expressing the IbpA/B proteins compared to WT bacteria cells. It may be assumed that the $6 \mathrm{xHis}$-ARHGAP6 protein expressed in MC4100 $\Delta i b p A / B$ cells lacking the IbpA and IbpB proteins instead of being held in an aggregated form by the IbpA/B proteins is effectively refolded by the DnaK/DnaJ chaperone system. Furthermore, it may be speculated that the lack of accumulated insoluble 6xHis-ARHGAP6 protein together with the suppression of promoter leaking by glucose are the factors responsible for cell viability during ARHGAP6 expression in $E$. coli cells. On the other hand, the reasons for the lack of expression of the 6xHis-ARHGAP6 protein in $\mathrm{Q} C 771 \Delta i b p A / B$ cells remain unknown. It may be assumed that in $\mathrm{QC} 771 \Delta i b p A / B$ cells besides the IbpA/B proteins other genome- determined factors influence the expression of foreign proteins.

In summary, the methodology described here allowed the production of soluble $6 \mathrm{xHis}$ ARHGAP6 protein in $E$. coli cells, which could be effectively purified by a simple two step procedure.

\section{R E F E R E N C E S}

Allen SP, Polazzi JO, Gierse JK, Easton AM. (1992) Two novel heat shock genes encoding proteins produced in response to heterologous protein expression in E. coli. $J$ Bacteriol.; 174: 6938-47.

Bradford MM. (1976) A rapid and sensitive method for the quantitation of microgram quantities of protein utilizing the principle of protein-dye binding. Anal Biochem.; 72: 248-54.

Chong LD, Traynor-Kaplan A, Bokoch GM, Schwartz MA. (1994) The small GTP-binding protein Rho regulates a phosphatidylinositol 4-phosphate 5-kinase in mammalian cells. Cell.; 79: 507-13.

Fried MG, Crothers DM. (1984) Equilibrium studies of the cyclic AMP receptor protein-DNA interaction. J Mol Biol.; 172: 241-62.

Hirschel BJ, Shen V, Schlessinger D. (1980) Lactose operon transcription from wild-type and L8-UV5 lac promoters in Escherichia coli treated with chloramphenicol. J Bacteriol.; 143: 1534-7.

Homma Y, Emori Y. (1995) A dual functional signal mediator showing RhoGAP and phospholipase C-delta stimulating activities. EMBO J.; 14: 286-91. 
Kitagawa M, Miyakawa M, Matsumura Y, Tsuchido T. (2002) Escherichia coli small heat shock proteins, IbpA and TbpB, protect enzymes from inactivation by heat and oxidants. Eur J Biochem.; 269: 2907-17.

Kucharczyk K, Laskowska E, Taylor A. (1991) Response of $E$. coli cell membranes to induction of $\lambda \mathrm{c} 1857$ prophage by heat shock. $\mathrm{Mol}$ Microbiol.; 5: 2935-45.

Kuczynska-Wisnik D, Kedzierska S, Matuszewska E, Lund P, Taylor A, Lipinska B, Laskowska E. (2002) The Escherichia coli small heat-shock proteins IbpA and IbpB prevent the aggregation of endogenous proteins denatured in vivo during extreme heat shock. Microbiology.; 148: 1757-65.

Laemmli UK. (1970) Cleavage of structural proteins during the assembly of the head of bacteriophage T4. Nature.; 227: 680-5.

Laskowska E, Wawrzynow A, Taylor A. (1996) IbpA and IbpB, the new heat-shock proteins, bind to endogenous Escherichia coli proteins aggregated intracellularly by heat shock. Biochimie.; 78: 117-22.

Miura Y, Kikuchi A, Musha T, Kuroda S, Yaku H, Sasaki T, Takai Y. (1993) Regulation of morphology by rho p21 and its inhibitory GDP/GTP exchange protein (rho GDI) in Swiss 3T3 cells. J Biol Chem.; 268: 1510-5.

Pan S-h, Malcolm BC. (2000) Reduced background expression and improved plasmid stability with pET vectors in BL21 (DE3). BioTechniques.; 29: 1234-8.

Paterson HF, Self AJ, Garrett MD, Just I, Aktories K, Hall A. (1990) Microinjection of recombinant $\mathrm{p} 21$ rho induces rapid changes in cell morphology. J Cell Biol.; 111: 1001-7.

Pawelczyk T, Matecki A. (1997) Expression, purification and kinetic properties of human recombinant phospholipase C $\delta 3$. Acta Biochim Polon.; 44: 221-30.

Pawelczyk T, Kowara R, Golebiowski F, Matecki A. (2000) Expression in Escherichia coli and simple purification of human Fhit protein. Protein Expr Purif.; 18: 320-6.
Prakash SK, Paylor R, Jenna S, Lamarche-Vane N, Armstrong DL, Xu B, Mancini MA, Zoghbi HY. (2000) Functional analysis of ARHGAP6, a novel GTPase-activating protein for RhoA. Hum Mol Genet.; 9: 477-88.

Rubin EJ, Gill DM, Boquet P, Popoff MR. (1988) Functional modification of a 21-kilodalton $\mathrm{G}$ protein when ADP-ribosylated by exoenzyme C3 of Clostridium botulinum. Mol Cell Biol.; 8: 418-26.

Sakowicz M, Grden M, Pawelczyk T. (2001) Expression level of adenosine kinase in rat tissues. Lack of phosphate effect on enzyme activity. Acta Biochim Polon.; 48: 745-54.

Sambrook J, Fritsch EF, Maniatis F. (1989) In Molecular cloning: a laboratory manual, 2nd edn., Cold Spring Harbor Laboratory Press, Cold Spring Harbor, NY.

Studier FW. (1991) Use of bacteriophage T7 lysozyme to improve an inducible T7 expression system. J Mol Biol.; 219: 37-44.

Sweet RW, Yokoyama S, Kamata T, Feramisco JR, Rosenberg M, Gross M. (1984) The product of ras is a GTPase and the T24 oncogenic mutant is deficient in this activity. Nature.; 311: 273-5.

Schaefer L, Prakash S, Zoghbi HY. (1997) Cloning and characterization of novel rho-type GTPase-activating protein gene (ARHGAP6) from the critical region for microphthalmia with linear skin defects. Genomics.; 46: 268-77.

Trahey M, McCormick F. (1987) A cytoplasmic protein stimulates normal N-ras p21 GTPase, but does not affect oncogenic mutants. Science.; 238: 542-5.

Veinger L, Diamant S, Buchner J, Goloubino P. (1998) The small heat-shock protein IbpB from Escherichia coli stabilizes stress-denatured proteins for subsequent refolding by a multichaperone network. J Biol Chem.; 273: 11032-7. 